\title{
Performance enhancement of split-phase induction motor by using fuzzy-based PID controller
}

\author{
Mohamed I. Abdelwanis, Ragab A. El-Sehiemy*
}

\begin{abstract}
This paper presents control and analysis of a split-phase induction motor (SPIM) to drive a centrifugal pumping system. An optimized proportional- integral and derivative (PID) controller, that is capable with a vector closed-loop split-phase induction motor control, is presented and its simulation results are discussed. The fine-tuning procedure is employed for fuzzy PID (FPID) controller parameters in order to sustain the motor speed at the predefined reference values. To assess the performance of the competitive controllers, conventional PID (CPID) and FPID, four operational indices for are suggested for measure the capability of the two controllers. These indices involve individual steady state error (ISSE) for each operating period, total steady state error (TSSE) for overall loading cycle, Individual oscillation index (IOI) and Total oscillation index (TOI), in order to measure the capability of the FPID compared with CPID. The performance of the SPIM accomplished with these performance indices is checked and tested on high and low speed levels. Pulse width modulation (PWM) based simulation studies were employed for SPIM using MATLAB/SIMULINK software. The results show that the overall performance of the SPIM operated with vector control that is tuned by FPID is enhanced compared with CPID.
\end{abstract}

K e y w or d s: centrifugal pumping system, fuzzy PID controller (FPID), pulse width modulation split-phase induction motor, steady state performance indices, vector control

\section{Nomenclature}

$T_{e}^{*}, T_{L} \quad$ reference electrical torque and load torque

$R_{a}, R_{m}, R_{r}$ resistances of auxiliary, main and rotor, $\Omega$

$\omega_{r}, n_{r} \quad$ rotor frame angular speed and rotational speed

$I_{d s}, I_{q s} \quad$ stator current components in the $d$-and $q$ axes respectively, $\mathrm{A}$

$L_{s a}, L_{s m}, L_{r}$ auxiliary, main and rotor inductances respectively, $\mathrm{H}$

$L_{m a}, L_{m m}$ auxiliary and main magnetization inductances, $\mathrm{H}$

$p \quad$ number of pole pairs

$T_{m}$ and $T_{a}$ main and auxiliary total number of turns

$V_{d s}, V_{q s} \quad$ direct and quadrature components of stator voltages

$\psi_{d s}, \psi_{q s} \quad$ direct and quadrature stator flux component

a main to auxiliary winding ratio

$J \quad$ motor inertia, $\mathrm{kg} \mathrm{m}^{2}$

$B \quad$ friction coefficient

$I / s \quad$ integration operator

$I_{m}, I_{a} \quad$ main and auxiliary winding currents, A

\section{Introduction}

The single-phase induction motor is better than polyphase motor especially in small power applications. Splitphase induction motor (SPIM) is rugged, very simple in its structure, and inherently appropriate for split-phase power supplies. The SPIM are used in several commercial and domestic applications like air conditioning fans, blowers, centrifugal pumps, washing machine, grinder, household appliances and lathes $[1,2]$. The new features and opportunities of this motor type have not been heavily researched due to its low rated power and rather limited industrial applications [1].

The construction of SPIM has main and auxiliary phases. Different speed control methods for variable speed operation of split-phase induction motor have already been created. The commonly employed speed control technique is the stator voltage/frequency control, where the motor terminal voltage and frequency are varied to obtain wide speed operation [3]. The overheating problem of the main winding at low speed drawback of application of variable speed methods for SPIM is. In the other side, this method is more suited for SPIM with high rotor resistance. Previously to control the IM operation, number of control methods were developed for this target such as vector control method, $\mathrm{V} / \mathrm{F}$ control and magnetic flux controller [4].

The development of artificial intelligence control techniques and their applications in different engineering areas has changed dramatically especially with the integration of fuzzy logic. In the last few decades, it was noticed the capability of fuzzy logic to overcome conventional controllers' challenges for increased systems complexity. In [5], fuzzy and ANFIS controllers were presented to control the interconnected combined cycle gas turbine.

* Department of Electrical Engineering, Faculty of Engineering, Kafrelsheikh University, Egypt, mohamed.soliman4@eng.kfs.edu.eg, elsehiemy@gmail.com 


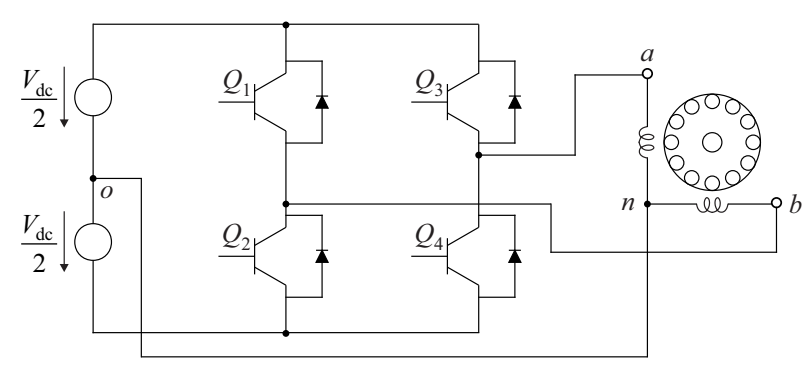

Fig. 1. Primary Single-phase inverter and two phase motor

While in [6-10], the fuzzy logic was developed for solving power systems problems as for finding the preventive emergency reactive power solution in [6] to control the operation switched reluctance machine [7], fuzzy controller of power system stabilizer to achieve acceptable levels of damped power system oscillations [8], employing speed control of the sensorless BLDC Motor Drive [9]. In [10], a fuzzy based framework was presented to find the optimal monitoring scheme using phasor measurement units in power systems.

The usage of fuzzy logic associated with CPID controller in [11] with an optimized controller's parameters. In [12], the FPID controller was employed for dual axis turntable servo system. Improved FPID controller is design using predictive functional control structure [13]. Simulation and control of a complex nonlinear dynamic behaviour of multi-stage evaporator using CPID and FPID controllers is presented in [14]. Tunned coefficients PI controller was applied on induction motor using hybrid algorithm that combines the merits of genetic and fuzzy logic for $\mathrm{V} / \mathrm{f}$ controller [15]. The scheduling of the CPID parameters was enhanced by fuzzy-logic to get the optimal system performance [16-18].

The Fuzzy logic based maximum torque control for a split-phase induction motor was presented in [19, 20]. Sensorless fuzzy speed control for split phase induction motors was presented in [21-24]. Hybrid neural-fuzzy control of the split-phase induction machine is given in [25]. High performance vector control of split phase induction motor was presented [26]. Hybrid FPID controller was presented to control speed of AC induction motor in [27] and [28]. In [29], the fuzzy logic was developed for speed control of single-phase induction motor. The main points of this paper are:

- Deriving the mathematical models of SPIM

- Providing the analytical study of the dq- equivalent circuit of SPIM.

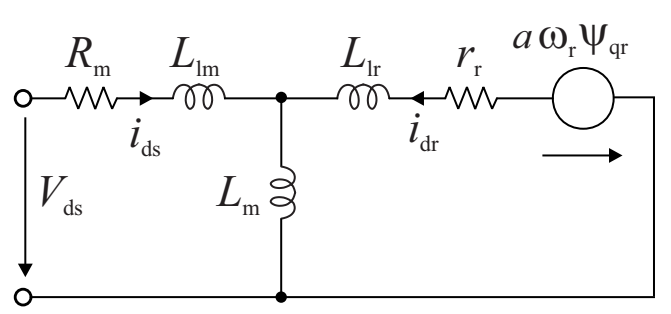

- Providing a fuzzy based closed loop control system for controlling the speed at high and low speed levels.

- Suggesting four operational indices, Individual steady state error, Total steady state error, Individual oscillation index, and Total oscillation index, in order to measure the capability of the FPID compared with CPID.

- The suggested indices are applied for motor speed, input current and the controller rise time.

- The proposed controller is tested for starting, peak, shoulder, accelerated speed at reduced torques loading conditions for the cycle of operation.

\section{Modelling and analysis of SPIM and its inverter}

\subsection{Single phase inverter}

To produce a variable sinusoidal wave form, the vector control and single-phase inverter are used to control the speed of the SPIM. Figure 1 presents the typical configuration of the single-phase inverter.

\subsection{Driving equations of the modified single-phase in- verter}

According to Kirchhoff voltage law (KVL), the driving equations to provide accurate analysis of voltage equations are presented as

$$
\begin{aligned}
& v_{a o}=v_{a n}+v_{n o}, \\
& v_{b o}=v_{b n}+v_{n o} .
\end{aligned}
$$

Adding (1) and (2) leads to the common voltage

$$
v_{n o}=\frac{1}{2}\left[v_{a o}+v_{b o}-v_{a n}-v_{b n}\right]
$$

\section{$2.3 d$-q model of SPIM}

In order to alleviate the time-change effects of inductances on the terminal voltage, the SPIM windings of stator and rotor sides are represented in Fig. 2, and the dq-axis reference frame which is a stationary reference farm [33]. The SPIM sinusoidal voltages can be expressed as $[31]$

$$
\begin{aligned}
& v_{a s}=V_{m} \sin (\omega t), \\
& v_{b s}=V_{m} \sin \left(\omega t+\frac{\pi}{2}\right) .
\end{aligned}
$$

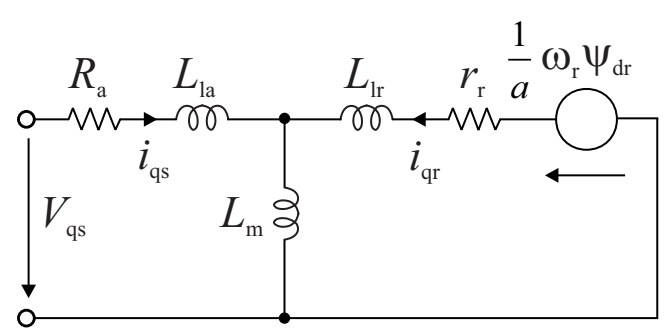

Fig. 2. dq- equivalent circuit of split phase induction motor 


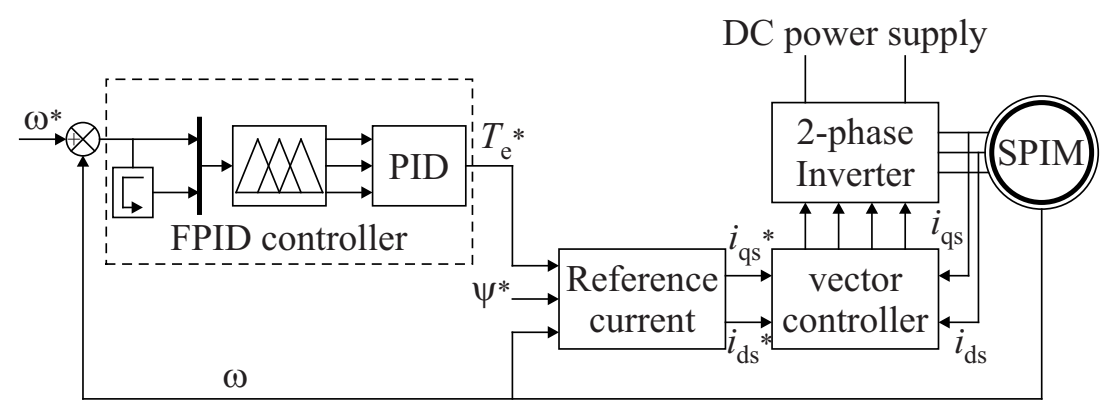

Fig. 3. Representation of the proposed FPID controller with vector controller

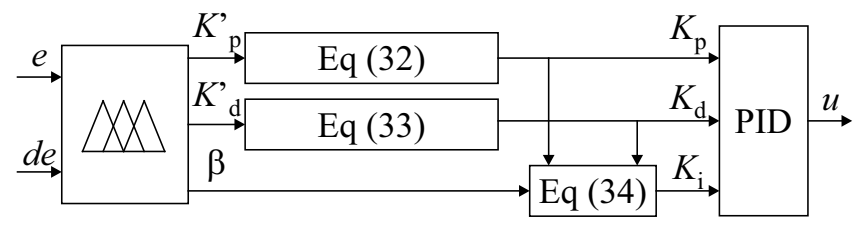

Fig. 4. Fuzzy based tuning of PID coefficients

The voltage components in the dq-axes decomposition can be reformulated as

$$
\begin{aligned}
V_{q} & =v_{m} \sin \left(\theta-\frac{\pi}{2}\right), \\
V_{d} & =v_{m} \sin (\theta) .
\end{aligned}
$$

In q-axis, the flux and current components of the stator and rotor are represented as in (8)-(11)

$$
\begin{aligned}
\psi_{q s} & =\frac{1}{s}\left[V_{q s}-R_{a} i_{q s}\right], \\
\psi_{q r} & =\frac{1}{s}\left[-R_{r} i_{q r}+\frac{1}{a} \omega_{r} \psi_{d r}\right], \\
i_{q s} & =\frac{1}{L_{s a}}\left[\psi_{q s}-L_{m a} i_{q r}\right], \\
i_{q r} & =\frac{1}{L_{r}}\left[\psi_{q r}-L_{m a} i_{q s}\right] .
\end{aligned}
$$

While, the flux and current components are presented as

$$
\begin{aligned}
\psi_{d s} & =\frac{1}{s}\left[V_{d s}-R_{m} i_{d s}\right] \\
i_{d s} & =\frac{1}{L_{s m}}\left[p s i_{d s}-L_{m m} i_{d r}\right] \\
\psi_{d r} & =\frac{1}{s}\left[-R_{r} i_{d r}+a \omega_{r} \psi_{q r}\right] \\
i_{d r} & =\frac{1}{L_{r}}\left[\psi_{d r}-L_{m m} i_{d s}\right]
\end{aligned}
$$

where $a=T_{m} / T_{a}$.

The motor torque and speed components are expressed as follows

$$
\begin{aligned}
T_{e} & =\frac{p}{2}\left[\psi_{q s} i_{q r}-\psi_{d s} i_{q r}\right], \\
\omega_{r} & =\frac{p}{2} \frac{1}{s}\left[\frac{1}{J}\left(T_{e}-T_{L}-B \frac{2}{p} \omega_{r}\right)\right], \\
n_{r} & =\frac{2}{p} \frac{60}{2 \pi} \omega_{r} .
\end{aligned}
$$

\section{Proposed design procedure of fuzzy controller of SPIM}

Figure 3 shows the proposed controller block diagram of the SPIM. The proposed controller aims to achieve reliable operation of the SPIM. As the vector control method has salient features as its simplicity and good accuracy of the estimated motor speed [18], the proposed controller involves the vector control method as shown in Figure 3. The main aim is to manage flux and stator current. The deviation between reference and measured speed

$$
e(t)=\omega_{r e f}-\omega_{r}
$$

is passed through FPID speed controller to produce a reference electrical torque

$$
T_{e}^{*}=F P I D e(t) .
$$

The reference direct and quadrature currents are

$$
\begin{aligned}
I_{d s 1}^{*} & =\frac{\psi_{r}^{*}}{L_{m}}, \\
I_{q s 1}^{*} & =\frac{2}{p} \frac{L_{r}}{L_{m}} \frac{T_{e}^{*}}{\psi_{r}^{*}} .
\end{aligned}
$$

The flux angle can be calculated from

$$
\theta_{e}^{*}=\frac{1}{s}\left[\frac{2 R_{r} L_{m} I_{q s 1}^{*}}{L_{r} \psi_{r}^{*}}+\omega_{m}\right] .
$$

The values of $I_{d s 1}^{*}$ and $I_{q s 1}^{*}$ are employed to obtain $i_{q s}^{*}$, $i_{d s}^{*}$

$$
\begin{aligned}
& i_{d s}^{*}=a I_{d s 1}^{*} \sin \theta_{e}^{*}+I_{q s 1}^{*} \cos \theta_{e}^{*}, \\
& i_{q s}^{*}=I_{d s 1}^{*} \cos \theta_{e}^{*}-I_{q s 1}^{*} \sin \theta_{e}^{*} .
\end{aligned}
$$

These phase currents $\left(i_{q s}^{*}, i_{d s}^{*}\right)$ are compared with the captured phase currents $\left(i_{q s}, i_{d s}\right)$ and the error signal is passed through hysteresis-band controller to generate switching pulses for voltage source inverter (VSI).

\subsection{Design of closed-loop control system}

To enhance the system performance, a closed-loop vector control was introduced. The deviation between the measured and reference speeds is defined as the error signal. The magnitude of error signal and its sign can be calculated from (19). Based on this error, the PID controller corrects the motor frequency deviation to recompense this error. The design of PID controller is required 


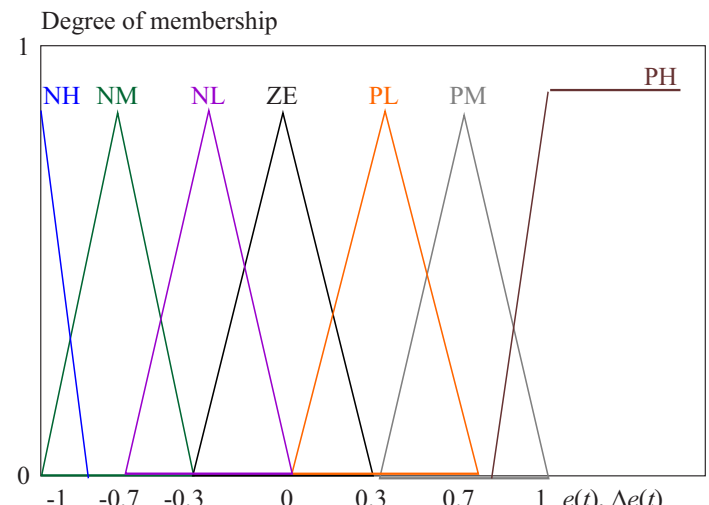

Fig. 5. Fuzzy modelling of input variables (error and change of error)

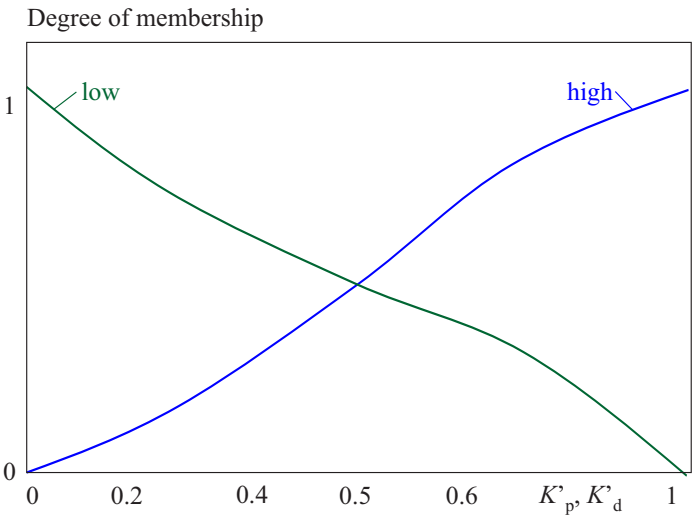

Fig. 6. Modelling for FPID coefficients $K_{p}^{\prime}, K_{d}^{\prime}$

Table 1. Fuzzy rules truth tables of the FPID controller

\begin{tabular}{lccccccccc}
\hline$e(t)$ & $\Delta e$ & $K_{p}^{\prime}$ & $K_{d}^{\prime}$ & $\beta$ & $e(t)$ & $\Delta e$ & $K_{p}^{\prime}$ & $K_{d}^{\prime}$ & $\beta$ \\
\hline \multirow{6}{*}{ NH, PH } & NH & high & low & VL & & NH & low & high & H \\
& NM & high & low & VL & & NM & low & high & L \\
& NL & high & low & VL & & NL & high & high & L \\
& ZE & high & low & VL & NL, PL & ZE & high & low & VL \\
& PL & high & low & VL & & PL & high & high & L \\
& PM & high & low & VL & & PM & low & high & L \\
& PH & high & low & VL & & PH & low & high & H \\
\hline & NH & low & high & L & & NH & low & high & VH \\
& NM & high & high & L & & NM & low & high & H \\
& NL & high & low & VL & & NL & low & high & L \\
NM, PM & ZE & high & low & VL & ZE & ZE & high & high & L \\
& PL & high & low & VL & & PL & low & high & L \\
& PM & high & high & L & & PM & low & high & H \\
& PH & high & high & L & & PH & low & high & VH \\
\hline
\end{tabular}

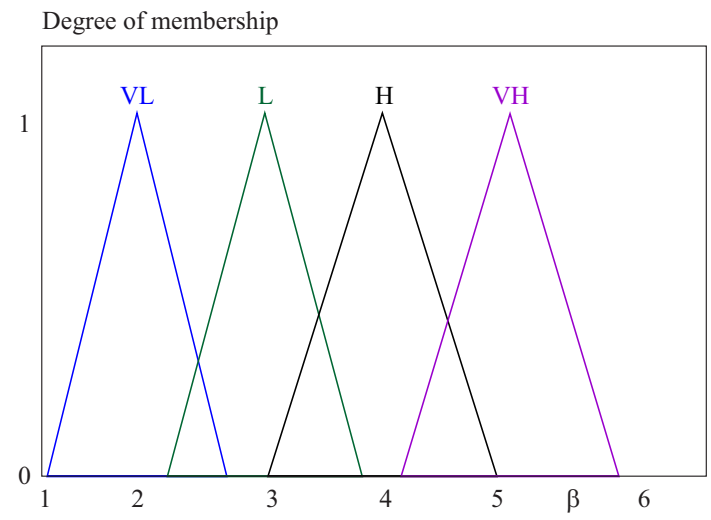

Fig. 7. Fuzzy modelling for weighting coefficient $\beta$

in order to determine the three coefficients: $K_{p}, K_{i}, K_{d}$, that minimize the cost function

$$
\begin{aligned}
& u(t)=K_{p} e(t)+K_{i} \int e(t) \mathrm{d} t+K_{d} \frac{\mathrm{d} e(t)}{\mathrm{d} t}, \\
& u(t)=K_{p} e(t)+\frac{K_{p}}{T_{i}} \int e(t) \mathrm{d} t+K_{p} T_{d} \frac{\mathrm{d} e(t)}{\mathrm{d} t},
\end{aligned}
$$

where, $T_{i}$ and $T_{d}$ are the integral and derivative time constants.

In the proposed FPID controller, the fuzzy system controls the PID parameters which are considered as the primary controller. In this regard, two signals, speed error and its change of error, are considered as the input variables to the fuzzy system while the output variables are the tunned PID coefficients $\left(K_{p}, K_{d}, K_{i}\right)$. The tuned PID parameters are employed to control the inverter input signal as shown in Fig. 4. The $K_{p}^{\prime}$ and $K_{d}^{\prime}$ are normalized, as in [32]

$$
K_{p}^{\prime}=\frac{K_{p \min }-K_{p}}{K_{p \min }-K_{p \max }}
$$

where $K_{p \min } \mathrm{n}$ and $K_{p \max }$ are the minimum and maximum limits of $K_{p}$ coefficient.

$$
K_{d}^{\prime}=-\frac{K_{d \min }-K_{d}}{K_{d \max }-K_{d \min }}
$$

where $K_{d \min }$ and $K_{d \max }$ are the minimum and maximum limits of $K_{d}$ coefficient.

The integral time constant $\left(T_{i}\right)$ by

$$
T_{i}=\beta T_{d} .
$$


Then, integral coefficient $K_{i}$ is computed from

$$
K_{i}=\frac{K_{p}}{\beta T_{d}}=\frac{K_{p}^{2}}{\beta K_{d}} .
$$

The tunned FPID coefficients are updated

$$
\begin{aligned}
& K_{p}=K_{p \min }+K_{p}^{\prime}\left(K_{p \max }-K_{p \min }\right) \\
& K_{d}=K_{d \min }+K_{d}^{\prime}\left(K_{d \max }-K_{d \min }\right) \\
& K_{i}=\frac{K_{p}^{2}}{\beta K_{d}}
\end{aligned}
$$

\section{Application}

\subsection{Simulated cases}

The capability of the proposed fuzzy based speed controller is proven via the MATLAB/Simulink by adopting the modelling of the SPIM-pumping system via two studied cases. The first case (Case 1) emulates the operation at high speed, (1480 rpm) while the second operation case (Case 2) emulates the operation at low speed, ( $800 \mathrm{rpm}$ ).

\subsection{Tunning of fuzzy PID controller}

Figure 4 shows the procedure of tuning various FPID parameters to obtain the healthy control indicator. The input variables are modeled in the fuzzed using 7 overlapped triangular fuzzy memberships as in Fig. 5. Similarly, the fuzzification process is employed for output variables as in Figs. 6 and 7. The boundaries of all the output $\left(K_{p}, K_{d}\right)$ are chosen as revealed in Fig. 6. The fuzzy modeling of coefficient which is demonstrated by using 4 fuzzy sets as shown in Fig. 7.

Each fuzzy input/output variable has degree of membership ( $\mu n$ the range $[0,1]$ ). The fuzzy inference system is implemented for the input and output variables with the aid of fuzzy rules defined in Table 1.

\subsection{Sequential operation of SPIM}

For the two conditions studied cases and CPID and FPID controllers, the sequential operation of a load cycle that is applied on SPIM, as shown in Fig. 8, are described as follows:

Period 1: in this mode the motor is operated at no load $\left(T_{L}=0 \mathrm{Nm}\right)$ This mode represents the starting mode that the motor starts from standstill speed until the rated speed. In this case the period is $0.5 \mathrm{~min}$.

Period 2: Peak loading condition: in this operation mode the motor is operated at nominal rated torque $\left(T_{L}=\right.$ 3) $\mathrm{Nm}$ for a period of $0.7 \mathrm{~min}$ ( $1.2 \mathrm{~min}$ from starting instant).

Period 3: in this operation mode the motor is operated at 0.5 rated torque $\left(T_{L}=1\right) \mathrm{Nm}$ from $1.2 \mathrm{~min}$ to $1.8 \mathrm{~min}$ from starting instant.
Period 4: shoulder loading condition in this operation mode the motor is operated at $\left(T_{L}=2\right) \mathrm{Nm}$ from $1.8 \mathrm{~min}$ to $2.5 \mathrm{~min}$.

Period 5: accelerated operating mode: this mode represents the transition from shoulder loading condition to peak loading condition within a period of $0.5 \mathrm{~min}$.

The split phase induction motor parameters are presented in Table 2.

Table 2. Tested SPIM parameters extracted from [30]

\begin{tabular}{lccc}
\hline$L_{\mathrm{lm}}(\mathrm{H})$ & 0.0203 & $R_{r}^{\prime}(\Omega)$ & 3.61 \\
$R_{m} \Omega$ & 4 & $L_{\mathrm{l} r}(\mathrm{mH})$ & 30.4 \\
$L_{\mathrm{la}}(\mathrm{H})$ & 0.021 & $P$ & 4 \\
$R_{a}(\Omega)$ & 6.5 & $I(\mathrm{~A})$ & 5.8 \\
$L_{m}(H)$ & 0.1954 & $V_{p h}(\mathrm{~V})$ & 220 \\
$f$ & $50 \mathrm{~Hz}$ & $J\left(\mathrm{kgm}^{2}\right)$ & 0.001424 \\
$P(h p)$ & 1 & $a=T_{a} / T_{m}$ & 1.1293 \\
\hline
\end{tabular}

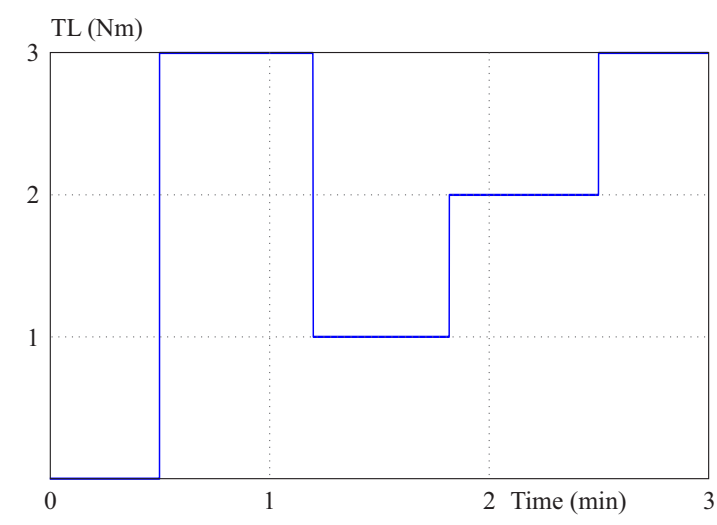

Fig. 8. Load torque characteristics

\subsection{Proposed evaluation indices}

To assess the performance of the FPID compared with CPID, four operational indices are considered for each of motor speed, input current and the controller rise time:

- Individual steady state error (ISSE): This index measures the deviation between the actual values of (speed/current/rise time) compared with their related the steady state values for specific period of the operation cycle

- Total steady state error (TSSE): This index measures the total deviation between the actual values of (speed/current/rise time) compared with their related steady state values for the operation cycle.

- Individual oscillation index (IOI): This index measures the oscillation between the actual values of the rise time compared with their related the steady values for specific period of the operation cycle.

- Total oscillation index (TOI): This index measures the total oscillation of the rise time for the overall cycle.

- Individual oscillation index (IOI): This index measures the oscillation between the actual values of the rise 
Table 3. Comparison of the proposed indices of FPID against CPID controllers of Case 1

\begin{tabular}{|c|c|c|c|c|c|c|c|c|c|c|c|c|}
\hline \multirow{2}{*}{ Index } & \multirow{2}{*}{ Controller } & \multicolumn{2}{|c|}{ Period $\# 1$} & \multicolumn{2}{|c|}{ Period $\# 2$} & \multicolumn{2}{|c|}{ Period \#3 } & \multicolumn{2}{|c|}{ Period $\# 4$} & \multicolumn{2}{|c|}{ Period $\# 5$} & \multirow{2}{*}{$\begin{array}{l}\text { Cycle } \\
\text { TSSE }\end{array}$} \\
\hline & & IOI & ISSE & IOI & ISSE & IOI & ISSE & IOI & ISSE & IOI & ISSE & \\
\hline \multirow{2}{*}{$\begin{array}{l}\text { Speed } \\
(\mathrm{rpm})\end{array}$} & CPID & 0.51 & 0.43 & 5.6 & 3 & 0.76 & 0.4 & 1.6 & 1 & 4.6 & 3 & 211.62 \\
\hline & FPID & 0.49 & 0.4 & 4 & 2 & 0.73 & 0.35 & 1.2 & 0.8 & 4 & 2.5 & 194.1 \\
\hline \multirow{2}{*}{$\begin{array}{l}\text { Current } \\
\text { (A) }\end{array}$} & CPID & 0.58 & 0.36 & 3.64 & 0.65 & 2.45 & 0.22 & 1.5 & 0.31 & 1 & 0.5 & 6.3 \\
\hline & FPID & 0.49 & 0.31 & 3.42 & 0.58 & 0.8 & 0.16 & 1.48 & 0.3 & 0.97 & 0.48 & 5.5 \\
\hline \multirow{2}{*}{$\begin{array}{l}\text { Rise time } \\
(\min )\end{array}$} & CPID & \multirow{2}{*}{\multicolumn{2}{|c|}{$\begin{array}{c}0.2 \\
0.08\end{array}$}} & \multicolumn{2}{|c|}{0.085} & \multicolumn{2}{|c|}{0.07} & \multicolumn{2}{|c|}{0.05} & \multicolumn{2}{|c|}{0.08} & 0.2 \\
\hline & FPID & & & \multicolumn{2}{|c|}{0.065} & \multicolumn{2}{|c|}{0.05} & \multicolumn{2}{|c|}{0.04} & \multicolumn{2}{|c|}{0.06} & 0.08 \\
\hline
\end{tabular}

Table 4. Comparison of the proposed indices of FPID against CPID controllers of Case 2

\begin{tabular}{|c|c|c|c|c|c|c|c|c|c|c|c|c|}
\hline \multirow[t]{2}{*}{ Index } & \multirow[t]{2}{*}{ Controller } & \multicolumn{2}{|c|}{ Period \#1 } & \multicolumn{2}{|c|}{ Period $\# 2$} & \multicolumn{2}{|c|}{ Period $\# 3$} & \multicolumn{2}{|c|}{ Period $\# 4$} & \multicolumn{2}{|c|}{ Period $\# 5$} & \multirow{2}{*}{$\begin{array}{l}\text { Cycle } \\
\text { TSSE }\end{array}$} \\
\hline & & IOI & ISSE & IOI & ISSE & IOI & ISSE & IOI & ISSE & IOI & ISSE & \\
\hline \multirow{2}{*}{$\begin{array}{l}\text { Speed } \\
(\mathrm{rpm})\end{array}$} & CPID & 1.23 & 0.87 & 1.5 & 0.6 & 2 & 0.6 & 1.15 & 0.6 & 2.42 & 0.63 & 233.77 \\
\hline & FPID & 1.15 & 0.81 & 1.45 & 0.5 & 1 & 0.4 & 1.02 & 0.3 & 2.16 & 0.5 & 227.28 \\
\hline \multirow{2}{*}{$\begin{array}{l}\text { Current } \\
\text { (A) }\end{array}$} & CPID & 1.41 & 0.49 & 1.83 & 0.7 & 1.12 & 0.37 & 1.06 & 0.56 & 0.94 & 0.65 & 5.59 \\
\hline & FPID & 1.37 & 0.57 & 1.75 & 0.67 & 0.95 & 0.31 & 1.01 & 0.53 & 0.87 & 0.58 & 3.45 \\
\hline \multirow{2}{*}{$\begin{array}{l}\text { Rise time } \\
(\min )\end{array}$} & CPID & \multirow{2}{*}{\multicolumn{2}{|c|}{0.1}} & \multicolumn{2}{|c|}{0.075} & \multicolumn{2}{|c|}{0.1} & \multicolumn{2}{|c|}{0.1} & \multicolumn{2}{|c|}{0.1} & 0.1 \\
\hline & FPID & & 0.07 & \multicolumn{2}{|c|}{0.065} & \multicolumn{2}{|c|}{0.06} & \multicolumn{2}{|c|}{0.061} & \multicolumn{2}{|c|}{0.065} & 0.07 \\
\hline
\end{tabular}

time compared with their related the steady values for specific period of the operation cycle.

- Total oscillation index (TOI): This index measures the total oscillation of the rise time for the overall cycle.

The previous indices reflect the capability of the FPID against CPID controllers in terms of enhancing the speed and current signals and the fast response of these controllers for certain period of operation or for the overall operation cycle.

\subsection{Simulation results}

1) Results of case 1: High speed

Figure 9 shows the CPID and FPID controllers speed variation. The estimation strategy is able to identify the accurate operation characteristics of the motor. In terms of two important indices called the rise time and steady state error, the proposed FPID controller has better performance. Figure 8 shows the five operation periods variation of load torque. It was cleared the FPID reaches the final speed rapidly compared with CPID. Figure 10 represents the main $\left(I_{m}\right)$ and auxiliary $\left(I_{A}\right)$ currents waveform vstime characteristics for the considered operation periods. In Figure 11, it was noticed a rapidly increase of the stator current in first period up to the highest current occurred at the starting instant. Then, the current was reduced to its rated value in 2-nd operating period. Figure 12 shows the quadrature to direct axis flux in five periods.
Figure 13 shows that $K_{p}$ is following the speed change as follows, is varied from 1.94 to 1.97 to reduce the time taken to ratch final speed values, $K_{i}$ is varied from 19 to 19.5 to reduce the time taken to ratch final speed values, and $K_{d}$ is varied from 0.19 to 0.21 to reduce the time taken to ratch final speed values.

According to Table 3, the proposed FPID controller has more profited indices when it was assessed compared with CPID controller for Case 1.

- The individual indices of the FPID controller in periods $1-5$, have low levels compared with those obtained with CPID controller.

- The TSSE is reduced from $211.62 \mathrm{rpm}$ to $194.1 \mathrm{rpm}$ for the speed signals.

- A reduction in the total current in the total cycle from $6.3 \mathrm{~A}$ to $5.5 \mathrm{~A}$ by $13 \%$.

- The resulted rise time of FPID controller is reduced to $40 \%$ compared with CPID controller.

2) Results of case 2: Low speed

Figure 14 shows the speed variation for CPID and FPID controllers. The estimation procedure effectiveness to identify the motor operation is cleared. Accordingly, in terms of the rise time and steady state error, the proposed FPID controller has better performance compared with the CPID controller. Figure 15 shows the current characteristics of both controllers.

Figure 16 shows that $K_{p}$ is following with speed variation as follows, it is varied from 1.975 to 2 in order to reduce the time taken to ratch final speed values, $K_{i}$ is 

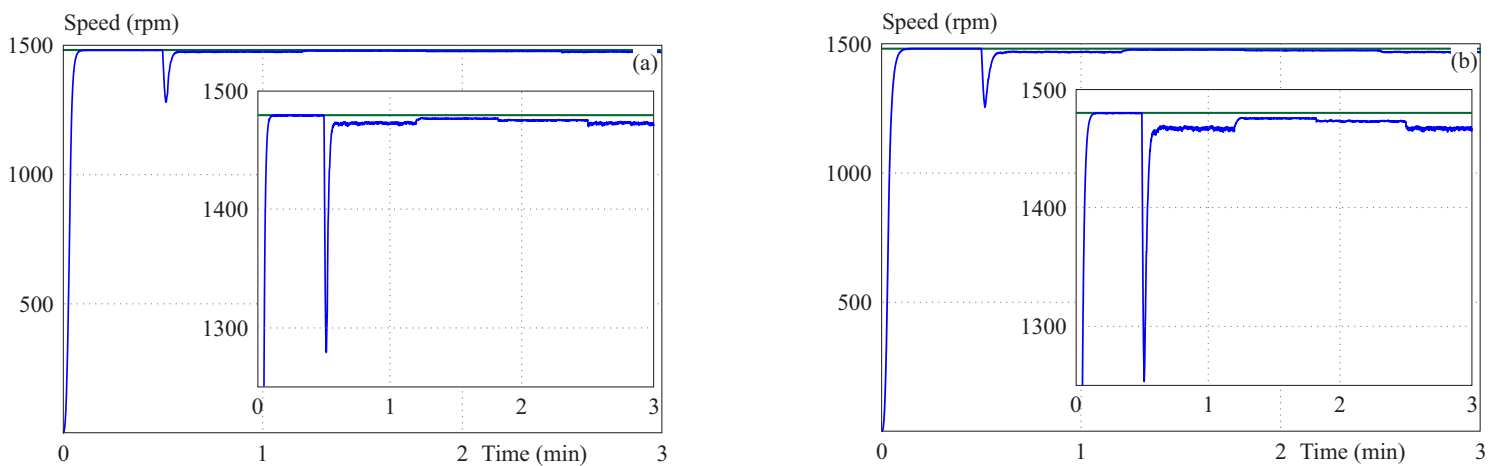

Fig. 9. Speed vs time characteristics for FPID and CPID controllers
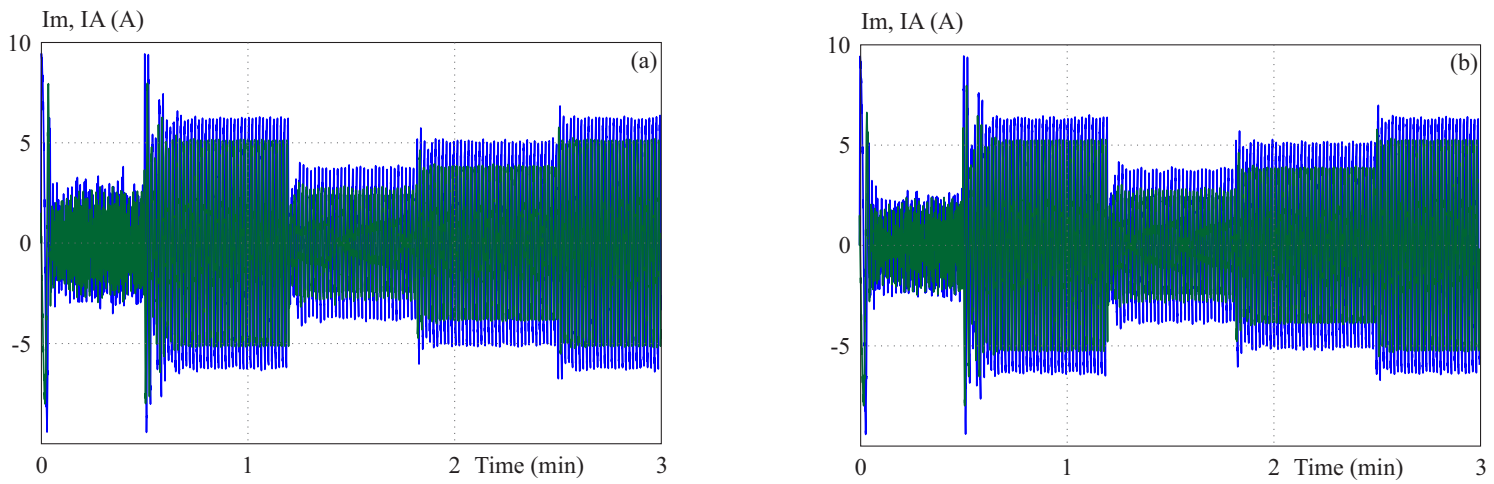

Fig. 10. 10 Main $\left(I_{m}\right)$ and auxiliary $\left(I_{a}\right)$ current wave form vs time characteristics
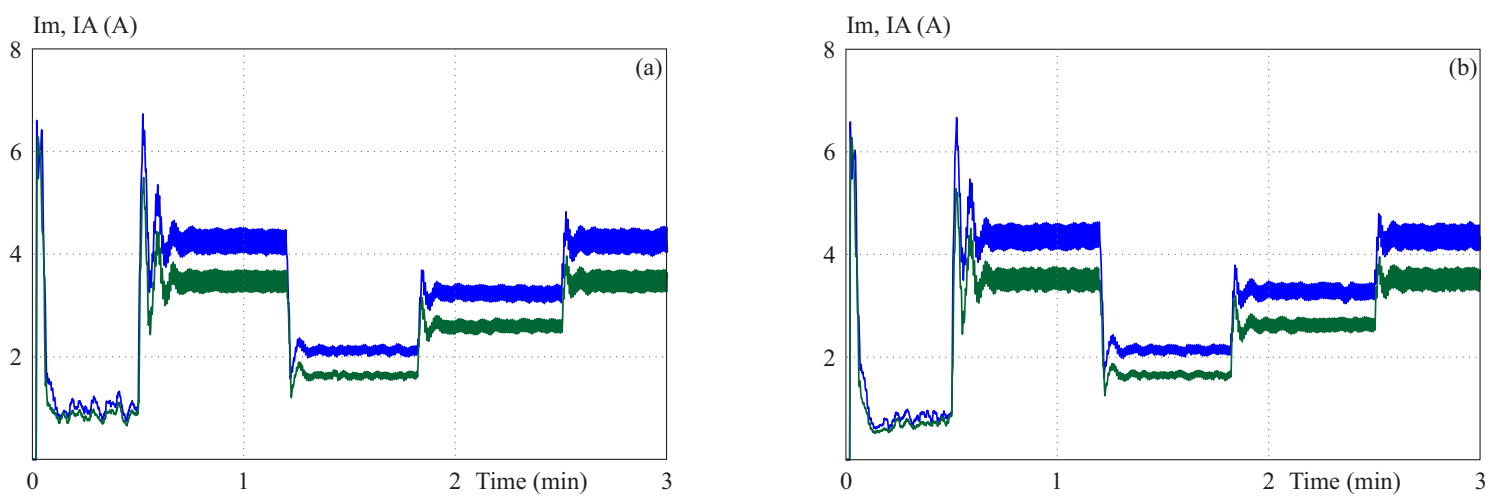

Fig. 11. Main $\left(I_{m}\right)$ and auxiliary $\left(I_{a}\right)$ currents vs time characteristics
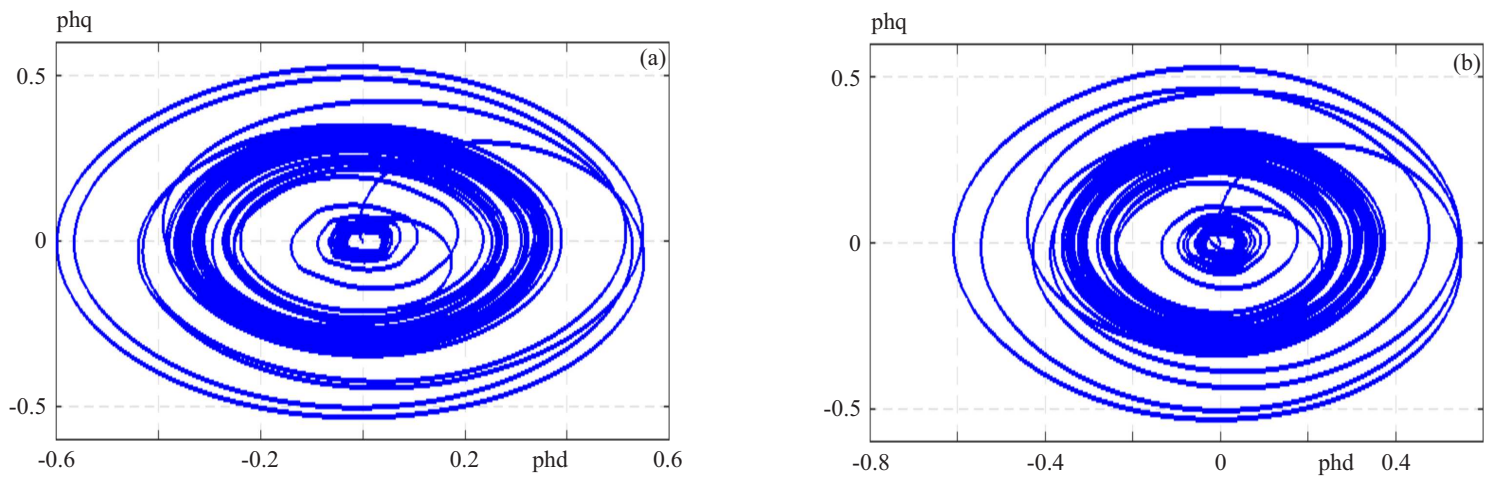

Fig. 12. Quadrature flux vs direct flux

varied from 19.7 to 20.05 to reduce the time taken to ratch final speed values, and $K_{d}$ is varied from 0.2 to 0.205 to reduce the time taken to ratch final speed val- ues. This shows that the value of FPID parameters is changed to enhance the performance of operation. Table 4 presents an assessment study between the proposed 

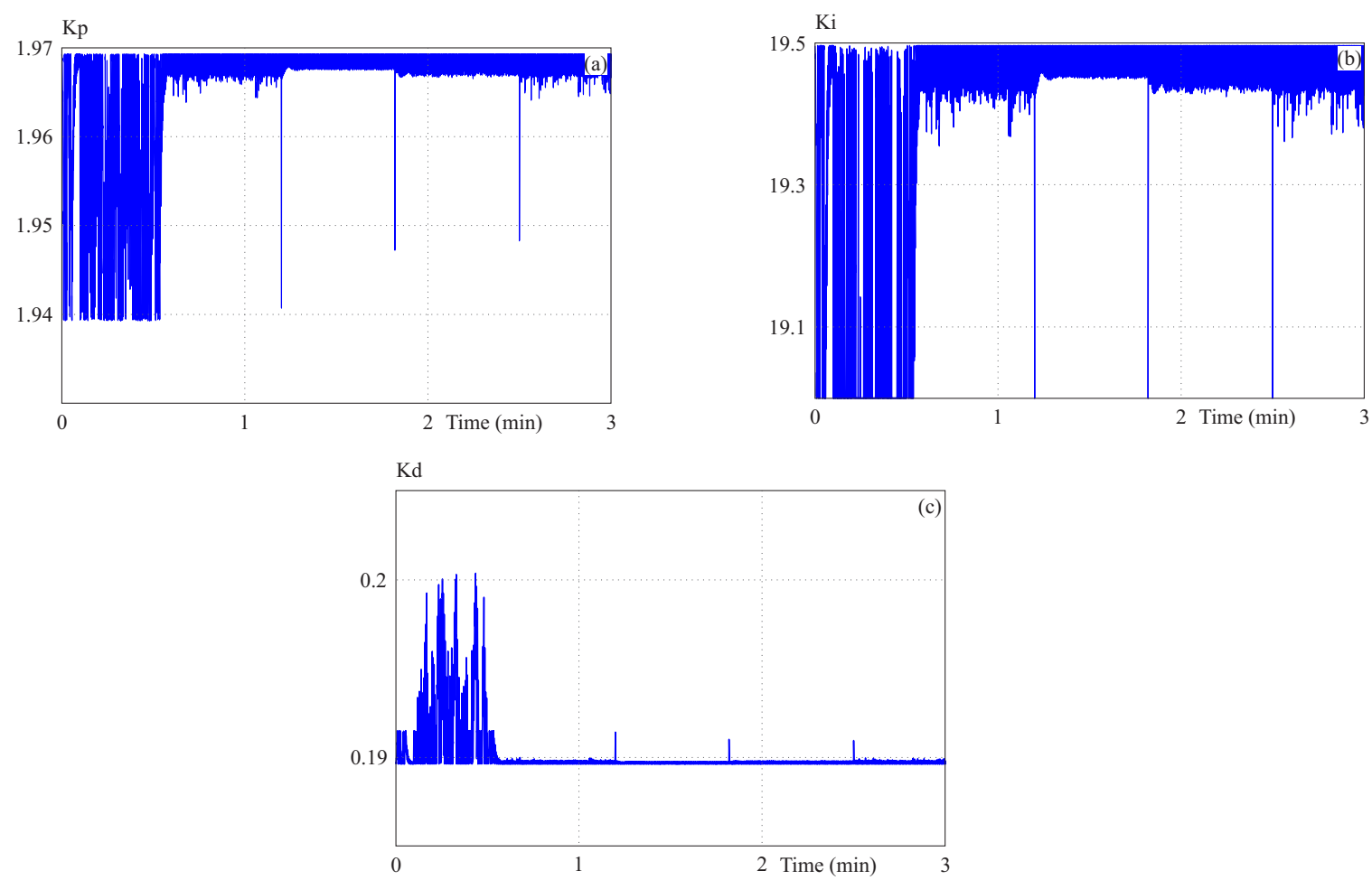

Fig. 13. Tunned FPID Parameters $\left(K_{p}, K_{i}, K_{d}\right)$ for Case 1
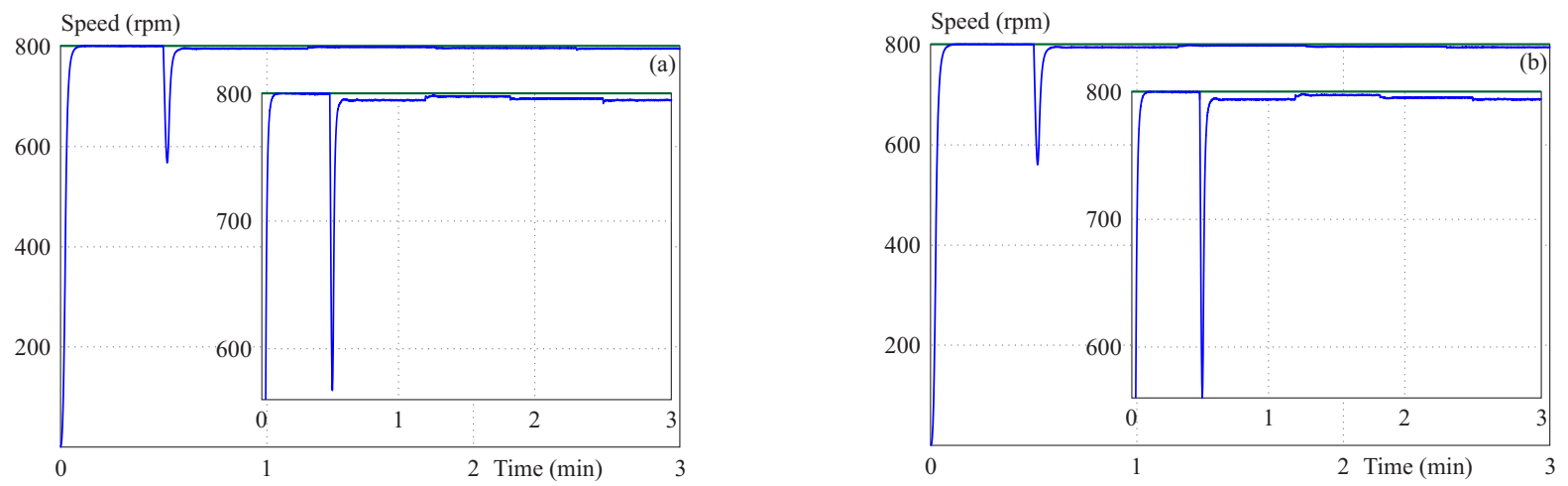

Fig. 14. Characteristics of speed vs time for FPID and CPID controllers for case 2

FPID and CPID controllers for the second case. It can be summarized the following benefits of FPID controller as:

- The individual speed overshot and the corresponding steady state error are reduced by using the FPID controller for period $1-5$.

- The TSSE is reduced from $233.77 \mathrm{rpm}$ to $227.25 \mathrm{rpm}$ for the speed signals.

- The resulted rise time of FPID controller is reduced to $70 \%$ compared with CPID controller.

- The current of FPID is improved compared with that of the CPID controller for the studied cases 5.59 A to $3.45 \mathrm{~A}$ by a reduction by $38 \%$ then enhancing motor performance by reducing the power losses to $38 \%$ of that of the CPID.

Table 5 shows a comparison of the proposed indices of FPID with those reported experimental results in [30]. It was cleared that the proposed FPID controller leads to enhanced performance for the three loading conditions. It has the lowest slip levels compared with CPID controller and the uncontrolled case extracted from [30].

Table 5. Comparison of the proposed indices of FPID against experimental value

\begin{tabular}{|c|c|c|c|c|c|c|}
\hline \multirow[b]{3}{*}{$\begin{array}{l}T_{L} \\
(\mathrm{Nm})\end{array}$} & \multicolumn{2}{|c|}{ Uncontrolled } & \multirow{2}{*}{\multicolumn{2}{|c|}{ CPID }} & \multirow{2}{*}{\multicolumn{2}{|c|}{ FPID }} \\
\hline & results & {$[30]$} & & & & \\
\hline & $\begin{array}{l}\text { speed } \\
(\mathrm{rpm})\end{array}$ & slip & $\begin{array}{l}\text { speed } \\
(\mathrm{rpm})\end{array}$ & slip & $\begin{array}{l}\text { speed } \\
(\mathrm{rpm})\end{array}$ & slip \\
\hline 3 & 1420 & 0.053 & 1467 & 0.022 & 1473 & 0.018 \\
\hline 2 & 1430 & 0.047 & 1473 & 0.018 & 1475.5 & 0.016 \\
\hline 1 & 1440 & 0.04 & 1475 & 0.016 & 1477 & 0.015 \\
\hline
\end{tabular}



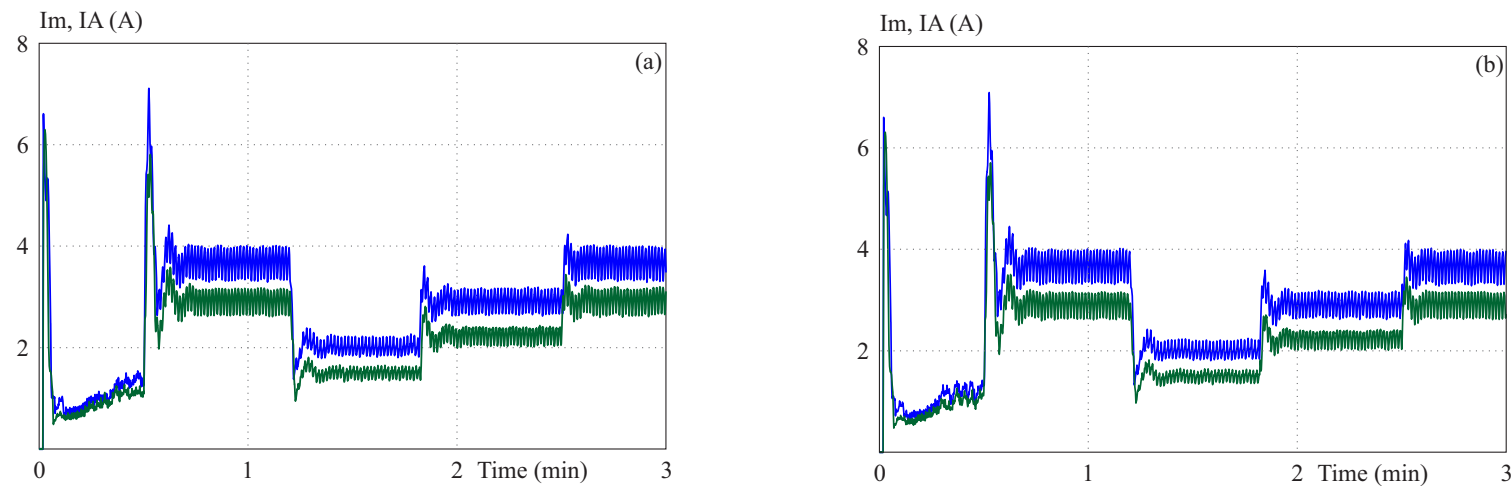

Fig. 15. Characteristics of current vs time for FPID and CPID controllers
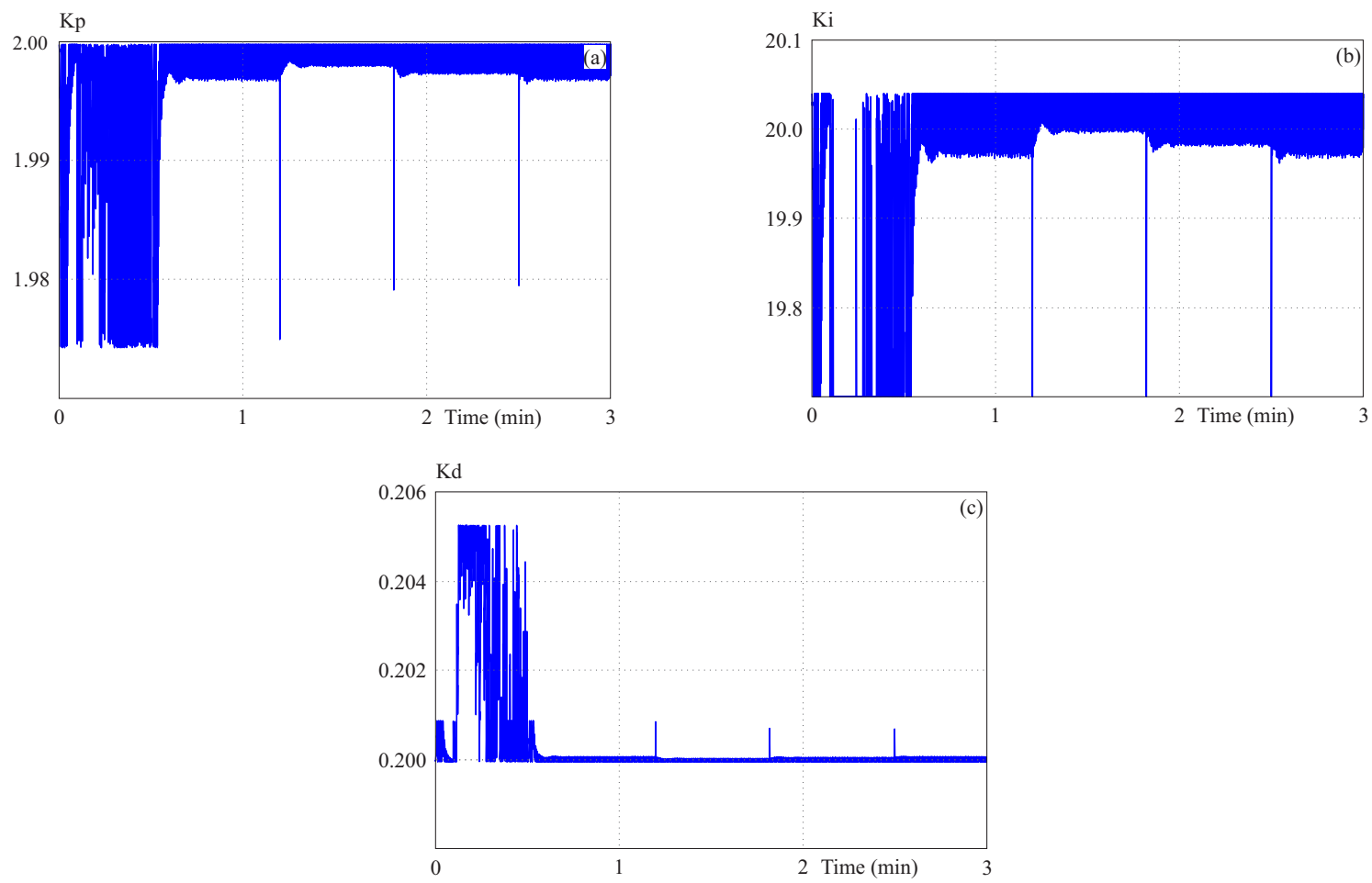

Fig. 16. Tunned PID Parameters by fuzzy control in Case 2

\section{Conclusions}

This paper has been discussed the implementation and analysis study of the split-phase IM. The PID coefficients are tuned using fuzzy-based tuning scheme to withstand the SPIM speed at the predefined reference values. The PID controllers have been combined with a vector closedloop controller for split-phase IM. The main features of the current paper can be summarized as follow:

- Providing the mathematical models of SPIM with analytical study of the dq-equivalent circuit of SPIM.

- Providing a fuzzy based closed loop control system for controlling the speed at high and low speed levels. The proposed FPID controller compared with CPID are enhancing the overall performance at acceptable levels of speed overshot, low current and low-rise time for low and high-speed operating conditions.
- The proposed fuzzy controller is assessed by four operational indices, Individual steady state error, total steady state error, individual oscillation index, and total oscillation index. The lowest levels of the previous indices prove the capability of the FPID compared with CPID.

- The proposed controller is tested for starting, peak, shoulder, accelerated speed at reduced torques loading conditions for the cycle of operation.

- Also, the FPID controller has the best performance for different loading conditions.

The directions for further research involve the application of fuzzy controller for polyphase machines and developing genetic, particle swarm, sine cosine optimization for tuning the membership degrees. Merging the neural network to the fuzzy logic to achieve fine tuning based on advanced learning schemes. 


\section{REFERENCES}

[1] J. Faiz, F. Kasebi, and P. Pillay, "Design Testing of an Integrated Electronically Controlled Capacitor for Integral Fractional Horse Power Single Phase Induction Motor", Energy conversion management vol. 45, no. 18-19, pp. 2989-3001, 2004.

[2] S. Vaez-Zadeh and A. Payman, "Design Analysis of Sensorless Torque Optimizaion for Single Phase Induction Motors", Energy conversion management vol. 47, no. 11-12, pp. 1464-1477, 2006.

[3] M. Jemli, H. B. Azza, and M. Gossa, "Real-Time Implementation of IRFOC for Single-Phase Induction Motor Drive using dSpace DS 1104 Control Board", Simulation Modelling Practice Theory vol. 17, no. 6, pp. 1071-1080, 2009.

[4] G. S. Ilango and N. Rajasekar, "An Improved Energy Saving v/f Control Technique for Solar Powered Single-Phase Induction Motor", Energy conversion Management vol. 50, no. 12, pp. 2913-2918, 2009.

[5] M. A. Elhosseini, R. A. El Sehiemy, A. H. Salah, and M. A. Abido, "Modeling Control of an Interconnected Combined Cycle Gas Turbine using Fuzzy ANFIS Controllers", Electrical Engineering vol. 100, no. 2, pp. 763-785, 2018.

[6] A. El-Sehiemy Ragab, "A Multi-Objective Fuzzy-Based Procedure for Reactive Power-Based Preventive Emergency Strategy", International Journal of Engineering Research Africa vol. 13, pp. 91-102, 2015.

[7] J. A. Domnguez-Navarro, "Fuzzy-Logic Strategy Control for Switched Reluctance Machine", Ecological Vehicles Renewable Energies (EVER) 2018 Thirteenth International Conference on. IEEE, 2018.

[8] Banna, Hasan Ul, et al "Performance Analysis of Conventional PSS Fuzzy Controller for Damping Power System Oscillations", Renewable Energy Research Application (ICRERA), International Conference on. IEEE, 2014.

[9] Verma, Vikas, Nidhi Singh Pal, and Bhavnesh Kumar "Speed Control of the Sensorless BLDC Motor Drive Through Different Controllers", Harmony Search Nature Inspired Optimization Algorithms, Springer, Singapore, pp. 143-152, 2019.

[10] A. El-Sehiemy Ragab, "A New Fuzzy Framework for the Optimal Placement of Phasor Measurement Units under Normal Abnormal Conditions", Resource-Efficient Technologies vol. 3.4, pp. 542-549, 2017.

[11] L. Du, X. Lu, M. Yu, B. Dong, and Y. Li, "Experimental Investigation on Fuzzy PID Control of Dual Axis Turntable Servo System", Procedia Computer Science vol. 131, pp. 531-540, 2018.

[12] Y. I. Kudinov, V. A. Kolesnikov, F. F. Pashchenko, A. F. Pashchenko, and L. Papic, "Optimization of Fuzzy PID Controller's Parameters", Procedia Computer Science 103, pp. 618622, (2017).

[13] Y. Wang, Q. Jin, and R. Zhang, "Improved Fuzzy PID Controller Design using Predictive Functional Control Structure", ISA Transactions vol. 71, pp. 354-363, 2017.

[14] O. P. Verma, G. Manik, and V. K. Jain, "Simulation Control of a Complex Nonlinear Dynamic Behavior of Multi-Stage Evaporator using PID Fuzzy-PID Controllers", Journal of Computational Science, 2017.

[15] S. V. Ustun and M. Demirtas, "Optimal Tuning of PI Coefficients by using Fuzzy-Genetic for V/f Controlled Induction Motor", Expert Systems with Applications vol. 34, no. 4, pp. $2714-2720,2008$.

[16] H. A. Kholerdi, "Chaotification Fuzzy PI Control of Three-Phase Induction Machine using Synchronization Approach", Chaos, Solitons \& Fractals vol. 91, pp. 443-451, 2016.

[17] W. Yuanxi, Y. Yali, Z. Guosheng, and S. Xiaoliang, "Fuzzy Auto-Adjust PID Controller Design of Brushless DC Motor", Physics Procedia vol. 33, pp. 1533-1539, 2012.

[18] Y. Sanjaya, A. Fauzi, D. Edikresnha, and M. M. Munir, "Single Phase Induction Motor Speed Regulation using a PID Controller for Rotary Force Spinning Apparatus", Procedia engineering vol. 170, pp. 404-409, 2017.

19] J. F. de Almeida, L. R. Valdenebro, and E. Bin, "Fuzzy Logic Based Maximum Torque Control for a Single-Phase Induction Motor", Industrial Electronics Society IECON'99 Proceedings, The 25thAnnual Conference of the IEEE, vol. 2, pp. 619-624, IEEE, 1999.

20] K. Bouhoune, K. Yazid, and M. S. Boucherit, "Fuzzy Logic Based Control of the Single Phase Induction Motor without Start-Capacitor", Power Engineering, Energy Electrical Drives (POWERENG), Fourth International Conference pp. 747-752, IEEE, 2013.

[21] D. Wang and Y. Shi, "Sensorless Fuzzy Speed Control for Single Phase Induction Motors", Fuzzy Systems Knowledge Discovery 2009. FSKD'09, $6^{\text {th }}$ International Conference vol. 4, pp. 163-165, IEEE, 2009.

22] D. Wang, "Sensorless Fuzzy Variable Speed Cotrol with Torque Optimization for the Improvements of Single Phase Capacitor-Run Induction Motors", Measuring Technology Mechatronics Automation (ICMTMA), International Conference, vol. 3, pp. 325-328, IEEE, 2010.

[23] D. Wang, "Hybrid Fuzzy Vector Control for Single Phase Induction Motor", Computing, Control Industrial Engineering (CCIE), 2010 International Conference, vol. 2, pp. 122-125, IEEE, 2010.

24] S. Shukla and B. Singh, "Single Stage PV Array Fed Speed Sensorless Vector Control of Induction Motor Drive for Water Pumping", IEEE Transactions on Industry Applications, 2018.

[25] K. Bouhoune, K. Yazid, and M. S. Boucherit, "Hybrid Neural-Fuzzy Control of the Single-Phase Induction Machine", Communications, Computing Control Applications (CCCA), International Conference, pp. 1-5, IEEE, 2011.

[26] A. B. Nanda and T. K. Bhattacharya, "High Performance Vector Control of Single Phase Induction Motor Drives based on Rotor MEMF", Energy, Automation, Signal (ICEAS), International Conference, pp. 1-5, IEEE, 2011.

[27] M. N. Uddin, M. M. Rashid, A. M. Tahir, M. Parvez, M. F. M. Elias, and M. M. Sultan, "Hybrid Fuzzy PID Controller-Based Inverter to Control Speed of AC Induction Motor", Electrical \& Electronic Engineering (ICEEE), International Conference, pp. 9-12, IEEE, 2015.

[28] G. Zigirkas and J. Kalomiros, "Intelligent Speed Controller for Single-Phase Induction Motors using Fuzzy APWM", Intelligent Data Acquisition Advanced Computing Systems: Technology Applications (IDAACS), $9^{\text {th }}$ IEEE International Conference, vol. 1, pp. 101-106, IEEE 2017.

29] K. Sapkota, A. Pradhan, A. K. Singh, and P. Rai, "Speed Control of Single-Phase Induction Motor using Fuzzy Logic Controller", Bera R. Sarkar S. Chakraborty S. (eds) Advances Communication, Devices Networking.Lecture Notes Electrical Engineering vol 462.Springer, Singapore, 2018.

30] S. Vaez-Zadeh and B. Zahedi, "Modeling Analysis of Variable Speed Single Phase Induction Motors with Iron Loss", Energy Conversion Management vol. 50, no. 11, pp. 2747-2753, 2009.

[31] T. H. Liu, M. T. Lin, and H. C. Wu, "A Single-Phase Induction Motor Drive with Improved Performance", Electric Power Systems Research vol. 47, no. 1, pp. 29-38, 1998.

[32] M. I. Abdelwanis and R. A. \& El-Sehiemy, "A Fuzzy-Based Controller of a Modified Six-Phase Induction Motor Driving a Pumping System", Iran J. Sci. Technol. Trans. Electr. Eng. (2018) https://doi.org/10.1007/s40998-018-0066-4.

[33] Do-Hyun Jang "Problems Incurred a Vector-Controlled Single-Phase Induction Motor", IEEE Transactions on Power Electronics vol. 28, no. 1, pp. 526-536, Jan 2013.

Received 26 October 2018 